\title{
Consistency in the reporting of sexual behavior among adolescent girls in Kenya: A comparison of interviewing methods
}

Paul C. Hewett

Population Council

Barbara Mensch

Population Council

Annabel Erulkar

Population Council

Follow this and additional works at: https://knowledgecommons.popcouncil.org/departments_sbsr-pgy

Part of the Demography, Population, and Ecology Commons, Family, Life Course, and Society Commons, Health Information Technology Commons, International Public Health Commons, and the Women's Health Commons

How does access to this work benefit you? Let us know!

\section{Recommended Citation}

Hewett, Paul C., Barbara Mensch, and Annabel Erulkar. 2003. "Consistency in the reporting of sexual behavior among adolescent girls in Kenya: A comparison of interviewing methods," Policy Research Division Working Paper no. 182. New York: Population Council. 
Consistency in the Reporting

$>$

$\mapsto$

of Sexual Behavior among

ค

Adolescent Girls in Kenya:

A Comparison of

I

u

Interviewing Methods

Paul C. Hewett

$\varangle$

Barbara S. Mensch

띠

Annabel S. Erulkar

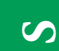

IT)

2003 No. 182

$\propto$

$\gg$

u

$\mapsto$

$\mapsto$

0

$\approx$

(P) Population Council 


\title{
Consistency in the Reporting of Sexual Behavior among Adolescent Girls in Kenya: A Comparison of Interviewing Methods
}

\author{
Paul C. Hewett \\ Barbara S. Mensch \\ Annabel S. Erulkar
}

Paul C. Hewett is Research Associate and Barbara S. Mensch is Senior Associate, Population Council, New York. Annabel S. Erulkar is Staff Program Associate, Population Council, Ghana.

The authors gratefully acknowledge the role of the project supervisors, Francis Ayuka (in Kisumu) and Arjmandbanu Khan (in Nairobi), as well as the 18 interviewers and three supervisors who carried out the field research in Kisumu. They also recognize the technical assistance provided by Stanley Mierzwa at the Population Council, New York, and Mike Shamku at the Population Council, Nairobi.

Funding for this research was provided by the National Institute of Child Health and Human Development (Grant R01 HD35700-02); by the Office of Population, Bureau for Global Health, US Agency for International Development, under the terms of Award No. HRN-A-00-99-00010; and by the Bill and Melinda Gates Foundation. 


\begin{abstract}
This paper explores the consistency in reporting of sexual behavior in a household survey of adolescents aged 15-21 in the Kisumu district of Kenya. Respondents were randomly assigned to different interviewing modes: face-to-face interviews, paper-and-pencil self-administered interviews, and audio computer-assisted self-interviewing (ACASI). The analysis focuses on the reporting of sexual behavior by adolescent girls in the face-to-face and ACASI modes and compares responses to a variety of questions about sexual activity, including sexual initiation, risky sexual behavior, and coerced sex. All sexual behavior questions were asked of each adolescent girl even if she answered "no" to the initial question about ever having had sex. The paper also compares the consistency of reporting for questions that were asked twice during the survey - once in the main interview and again in a face-to-face exit interview. By comparison with ACASI, the interviewer-administered mode produces highly consistent reporting of sexual activity both within the main interview and between the main and exit interviews. On the other hand, ACASI produces higher reporting of sex with a relative, stranger, or older man, and higher reporting of coerced sex. We argue that the level of consistency and the high response rates in the interviewer-administered mode are suspect and suggest reasons why one might expect inconsistent responses to survey questions about sexual behavior.
\end{abstract}

This material may not be reproduced without written permission from the authors. For a list of Policy Research Division Working Papers, including those available for downloading in PDF format, see www.popcouncil.org/publications/wp/prd/rdwplist.html. 
In sub-Saharan Africa, where the major route of transmission of HIV is through heterosexual intercourse and where rates of infection among young people, particularly adolescent girls, are high, it is critical to collect accurate information on sexual activity prior to marriage (UNAIDS 1998; UNAIDS and WHO 1998). Yet recent studies from the region raise questions about the accuracy of reporting of sexual behavior. An analysis of trends in age at first sex in Africa using the Demographic and Health Surveys indicates discrepancies in reporting within birth cohorts, consistent with young women denying and young men exaggerating their sexual activity (Zaba et al. 2002). An epidemiological investigation of the large gender disparity in HIV prevalence among young people in two African cities reveals HIV prevalence to be high among women reporting one sexual partner and few episodes of sexual intercourse, a pattern suggesting considerable underreporting of risky sexual behavior among young women (Glynn et al. 2001).

In previously published research on the effects of interview mode on the reporting of sensitive behavior in Nyeri and Kisumu districts in Kenya, we evaluated whether audio computer-assisted self-interviewing (ACASI) produced more credible data than interviewer-administered and paper-and-pencil self-administered interview methods, using survey data from more than 6,000 unmarried young people aged 15-21 (Mensch, Hewett, and Erulkar 2003). The results from Nyeri were, for the most part, inconsistent with our expectations. For instance, we anticipated that adolescent girls would have higher reporting of sex if assigned to ACASI because that interviewing method was presumed to provide greater privacy in which to answer sensitive questions. Yet respondents were significantly more likely to report sexual activity in face-to-face interviews. The findings for boys, although more in line with expectations, were not strong or consistent enough to suggest that ACASI was the preferred method of interviewing.

We posited that the results obtained in Nyeri for ACASI were not as expected because of the particular circumstances that existed in the district at the time, circumstances that adversely affected data collection. Given the volatile political climate in Nyeri, outsiders were often met with hostility and distrust. The district is composed largely of Kikuyus and was the center of political opposition in a country where divergent views were not well tolerated. ${ }^{1}$ The experience of our interviewing team-illus- 
trated by their fieldwork journals and diaries - indicated that the use of computers heightened the anxiety, suspicion, and hostility of the population. We suspect that any benefits that ACASI provided in terms of increased anonymity were masked by the negative reaction to the computer.

The results from Kisumu, where fieldwork went more smoothly, revealed that ACASI was better at obtaining more accurate reporting of sensitive behaviors. For the most part, ACASI generated significantly higher levels of reporting of sensitive behavior among girls, particularly among girls enrolled in school. For boys, who we believe exaggerate their level of sexual activity in face-to-face interviews, the reporting of girlfriends and premarital sex was lower with ACASI whereas reporting of more stigmatized behaviors was higher.

In this paper, we explore the consistency of reporting of sexual behavior among female respondents in Kisumu. We take advantage of the fact that in Kisumu, in contrast to Nyeri, all the sexual behavior questions were asked of every respondent, even those who answered negatively to an initial question about ever having had sex. We also compare responses to questions about sexual behavior in the main interview with responses in an exit interview where all respondents, including those in the ACASI group, were given a face-to-face interview.

\section{Background and Literature ${ }^{2}$}

Computer-assisted interviewing technologies have been in existence for more than three decades. ${ }^{3}$ With the introduction of personal computers, computerized interviewing has become more popular among survey researchers, primarily because it is believed to improve the quality of survey data while decreasing the cost of collection. Interviewing programs offer a variety of advantages over paper-and-pencil surveys, including entry validation, automated skip and branching for complex questionnaires, and internal consistency checks. Computerized interviews also eliminate the need for secondary data entry and cleaning, further enhancing data quality by avoiding keystroke errors (Couper and Nicholls 1998).

A large number of empirical studies have been conducted in developed countries to test whether computerized interviews encourage greater reporting of sensitive behaviors. Such studies typically use experimental designs to randomly assign respondents to 
different interview modes. A wide range of sensitive questions have been included in these analyses, including questions about sexual behavior (Turner et al. 1998; Tourangeau and Smith 1996), drug and alcohol use (Acquilino 1994; Acquilino and Lo Scuito 1990; Beebe et al. 1998), racial attitudes (Kyrsan 1998), and induced abortion (Fu et al. 1998). Although some studies have found little difference between computerized and noncomputerized self-administration (Jobe et al. 1997; Johnson et al. 2001; Millstein and Irwin 1983), consistently higher reporting is found when comparing CASI and ACASI to interviewer-based surveys (Turner et al. 1998; Tourangeau and Smith 1996; Fu et al. 1998; O’Reilly et al. 1994).

Other researchers have examined the reporting of sexual behavior and drug use specifically in relation to the risk of sexually transmitted diseases and HIV (Macalino et al. 2002; Fenton et al. 2001; Metzger et al. 2000). This research has focused on reporting and participation biases both in high-risk groups (Williams et al. 2000; Des Jarlais et al. 1999; Boekeloo et al. 1994) and in the general population (Johnson et al. 2001; Copas et al. 1997). These studies have generally found increased reporting of intravenous drug use, multiple sexual partners, and unprotected sex with CASI and ACASI. The conclusion that has emerged from these studies is that computerized administration increases the reporting of sensitive behaviors, while also providing a more efficient and effective means to implement self-administered surveys.

Although numerous studies in developing countries have also focused on sensitive behaviors - particularly sexual behavior — and although the cultural and traditional values of many countries indicate that candid reporting of such behaviors is unlikely (Mensch, Hewett, and Erulkar 2003), survey researchers have only recently begun to use CASI and ACASI technologies. Research exploring computerized interviewing in developing countries includes small-scale feasibility studies in Zimbabwe (van de Wijgert et al. 2000), Kenya (Voeten et al. 2000), and Thailand (Rumakom et al. 1999), and a more extensive study of alternative interviewing methods in Mexico (Lara et al. 2001).

\section{RESEARCH DESIGN AND SAMPLE}

The data collection for this paper was carried out in Kisumu district in Nyanza province, Kenya. Kisumu is located some 200 kilometers northwest of Nairobi. Its population in 1999 was approximately 500,000, with the majority belonging to the Luo eth- 
nic group. Over 40 percent of the population lives in urban and peri-urban areas, with the rest residing in rural areas. ${ }^{4}$ The workforce is primarily engaged in subsistence farming, animal husbandry, and fishing. As a connection point in the rail line running from Kampala, Uganda to Mombasa, Kenya, Kisumu also has a small industrial and manufacturing base.

Kisumu was selected for this study because it has one of the highest HIV prevalence rates in Kenya (Buvé et al. 2001), heightening the importance of capturing accurate levels of adolescent sexual activity and contraceptive use. The median age at first sex in the district is 16.5 years, slightly lower than the national average of 16.7. Women in Kisumu also report greater levels of sexual activity than Kenyan women generally, 70 percent versus 62 percent. $^{5}$

The study was based on an experimental design in which unmarried adolescents were randomly assigned to one of three interview methods: face-to-face interviews, paper-and-pencil self-administered interviews, and ACASI interviews. Randomly sampled enumeration areas from which households were selected were drawn using population estimates from the 1999 national census. ${ }^{6}$ Fieldwork took place between April and July 2002 and included interviews with approximately 2,100 adolescent boys and girls aged 15-21. ${ }^{7}$ To achieve the target number of respondents, fieldworkers identified all household members within a selected enumeration area in the days prior to interviewing adolescents. If there was an adolescent in the household, he or she was randomly assigned to one of the three interview modes. ${ }^{8}$ Male and female interviewers were trained for each mode and interviewed only same-sex respondents. To facilitate community acceptance, interviewers were recruited from the district, ensuring that they were from the same ethnic group as the respondent and spoke the local language. The interviewers were also relatively young, ranging in age from 20 to the mid-30s, and many had previous survey interviewing experience.

The ACASI computer program was configured so that respondents listened to questions and response categories through audio-headphones. Although the questions could have been simultaneously displayed on the computer screen, the computer remained closed during the interview. The respondent answered questions by pressing a number on an external mini-keypad that corresponded to a response category. 
The questionnaire included 69 questions; two-thirds were considered sensitive, asking respondents about their sexual behavior, alcohol and drug use, contraceptive practice, pregnancies, induced abortions, and births. A face-to-face exit interview conducted at the end of the main interview queried respondents regarding their feelings about the survey and the interview. The exit interview also included questions for the interviewer concerning the context of the interview, for example whether anyone else was present during the interview and whether the respondent had trouble completing the questionnaire.

For simplicity of presentation, only the results for the interviewer and ACASI surveys are discussed here. Although significant differences in reporting were sometimes found between the self-administered method and the interviewer and ACASI modes in Nyeri and Kisumu, the self-administered method rarely outperformed the other interview modes in obtaining higher levels of reporting of sensitive behaviors (Mensch, Hewett, and Erulkar 2003). Thus, the self-administered method is of less interest in evaluating the optimal method of eliciting higher reporting. The self-administered method also had a higher rate of missing or nonresponse data (Hewett, Erulkar, and Mensch 2003).

For clarity of exposition and to more fully explore the issue of response consistency, we restrict ourselves to adolescent girls. Fieldworkers interviewed 349 unmarried adolescent girls face-to-face and 360 with ACASI. Appendix Table 1 describes characteristics of the respondents.

\section{ANALYSES AND RESUlts}

The questions used for the analyses are listed in Table 1. We modified the questionnaire for Kisumu on the basis of our experiences in Nyeri. If respondents in Nyeri answered "no" to the question "Have you ever had sexual intercourse?," the interview was terminated. In Kisumu, as we noted above, all respondents regardless of their response to that question were asked further questions about their sexual behavior. Thus, even though a respondent may have answered "no" to ever having had sex, she was still asked "Have you ever had sex with a boyfriend?," "Have you ever had sex with a stranger?," and so on. ${ }^{9}$ 
Table 1 Questions from the Kisumu survey used in analysis

Have you ever had sexual intercourse?

\section{Sexual partners}

Have you ever had sexual intercourse with...

a boyfriend?

a friend, schoolmate, or acquaintance?

a relative?

a stranger?

a man ten or more years older than you?

\section{Coerced sex}

Have you ever been tricked by a boy into having sex when you did not want to?

Have you ever been locked in a room by a boy to have sex when you did not want to?

Have you ever been physically forced to have sex when you did not want to?

\section{Exit interview questions ${ }^{\mathrm{a}}$}

Have you ever had sexual intercourse?

In the last week, have you gone to the market or shopping center?

In the last week, have you boarded a bus or matatu ${ }^{\mathrm{b}}$ alone?

Have you ever gone to the market without your parents' permission?

Have you ever sneaked out at night without your parents' permission?

aThese questions were also asked verbatim in the main survey.

${ }^{\mathrm{b}}$ A private, largely unregulated, van used as a means of public transport.

The questions in Table 1 produce dichotomous indicators of sexual behavior; hence logistic regression analysis was used to obtain estimates of the differences in reporting by interview mode. In addition to evaluating the effect of interview mode, the logistic regressions include background variables that capture heterogeneity not controlled for by the study's experimental design. ${ }^{10}$ The results are presented as odds ratios, with the interviewer-administered mode serving as a baseline. Predicted percentages are also provided for ease of interpretation.

Table 2 presents the odds ratios and predicted probabilities for the estimation of premarital sexual activity for adolescent girls in Kisumu district. (A similar table, including results from Nyeri, appears in Mensch, Hewett, and Erulkar 2003.) Premarital sex in Table 2 is defined by whether respondents, all of whom are unmarried, report ever having had sexual intercourse. As can be observed, there is no clear pattern by interview mode. Without control variables, the base model indicates that reporting for ACASI is lower than for the interviewer-administered mode, although this result is not significant. The direc- 
Table 2 Odds ratios from logistic regression of ever having had sex: Adolescent girls

\begin{tabular}{|c|c|c|}
\hline & Base model & Full model \\
\hline \multicolumn{3}{|l|}{ Interview mode } \\
\hline Interviewer-administered & 1.00 & 1.00 \\
\hline ACASI-administered & .80 & 1.22 \\
\hline \multicolumn{3}{|l|}{ Respondent characteristics } \\
\hline Age & & $1.38 * * *$ \\
\hline Ethnicity: Luo & & 1.21 \\
\hline Urban, peri-urban residence & & 1.04 \\
\hline Catholic & & 1.20 \\
\hline No. of times attended church in the last week & & 0.84 \\
\hline Completed primary school & & 0.90 \\
\hline Attended, completed secondary school & & $0.36 *$ \\
\hline Currently enrolled in school & & $0.36 * * *$ \\
\hline Currently works for cash & & $1.98 *$ \\
\hline \multicolumn{3}{|l|}{ Household structure } \\
\hline Lives with both parents & & 0.86 \\
\hline Lives with one parent & & 0.83 \\
\hline No. of adolescent boys in household & & 0.80 \\
\hline No. of adolescent girls in household & & 0.80 \\
\hline No. of people slept in household previous night & & 1.03 \\
\hline \multicolumn{3}{|l|}{ Household characteristics } \\
\hline No. of items owned: livestock, cash crops, or land & & 1.10 \\
\hline Household has piped water & & 0.85 \\
\hline Household has well water & & 1.29 \\
\hline Household has flush toilet & & 0.48 \\
\hline Household has finished floors & & 1.30 \\
\hline Household has electricity & & 0.94 \\
\hline No. of rooms used for sleeping & & 0.90 \\
\hline Sample size & 692 & 650 \\
\hline \multicolumn{3}{|l|}{ Predicted percentages by interview mode } \\
\hline Interviewer-administered & 48.1 & 48.3 \\
\hline ACASI & 42.6 & 42.8 \\
\hline
\end{tabular}

$* \mathrm{p}<.05 * * \mathrm{p}<.01 * * * \mathrm{p}<.001 ;$ standard errors adjusted for stratification and clustering in the sample design.

tion of results by interview mode changes as demographic variables are introduced, although again the results are not statistically significant. The predicted percentages reveal a pattern of results similar to those found in Nyeri, reporting of sex being about 5 percentage points lower with ACASI. The difference in the direction of the predicted values relative to the odds ratio is a function of the distribution of the independent variables by interview 
mode. For instance, compared to those interviewed face-to-face, ACASI respondents are more likely to be enrolled in school, have slightly higher educational attainment, and attend church more often, all factors negatively associated with premarital sex.

Table 3 provides odds ratios and predicted percentages by interview mode for questions about sexual partners and coerced sex. Note that the full set of control variables is included in these models. ${ }^{11}$ The results shown in Table 3 are substantially different from those observed in Table 2. With the exception of sex with a boyfriend, which parallels the results for the "ever had sex" question in Table 2, the log odds for each sex partner are significantly greater in the ACASI administration. This pattern is also observed for coerced sex. ACASI respondents are more than six times as likely to report having had sex with a friend, schoolmate, or acquaintance. They are more than three times as likely to report having sex with a stranger or a man ten or more years older, compared with respondents in the interviewer-administered group. ACASI respondents are also three times more likely to report being coerced to have sex. The associated predicted percentages are equally striking. While only one percent of young women were willing to admit to an interviewer that they had sex with a relative, over 20 percent

Table 3 Odds ratios and predicted percentages from logistic regression of sexual partners and coerced sex ${ }^{\mathrm{a}}$

\begin{tabular}{lccccc}
\hline & \multicolumn{2}{c}{ Log odds } & & \multicolumn{2}{c}{ Predicted percent } \\
\cline { 2 - 3 } & $\begin{array}{c}\text { Interviewer } \\
\text { admin }\end{array}$ & $\begin{array}{c}\text { Audio-CASI } \\
\text { admin }\end{array}$ & & $\begin{array}{c}\text { Interviewer } \\
\text { admin }\end{array}$ & $\begin{array}{c}\text { Audio-CASI } \\
\text { admin }\end{array}$ \\
\hline Ever had sex with & 1.00 & 1.16 & & 45.7 & 39.9 \\
Boyfriend & 1.00 & $6.26^{* * *}$ & & 9.8 & 32.0 \\
Friend, schoolmate, acquaintance & 1.00 & $42.60^{* * *}$ & & 1.0 & 20.9 \\
Relative & 1.00 & $3.45^{* * *}$ & & 3.7 & 14.2 \\
Stranger & 1.00 & $3.55^{* * *}$ & & 3.7 & 14.1 \\
Man ten or more years older & & & & \\
Coerced sex & 1.00 & $3.62^{* * *}$ & & 7.2 & 19.0 \\
Tricked & 1.00 & $2.74^{* * *}$ & & 5.7 & 14.0 \\
Locked in a room $^{\mathrm{b}}$ & 1.00 & $2.73^{* * *}$ & & 6.0 & 15.9 \\
Physically forced $^{\mathrm{b}}$ & & & & & \\
\hline
\end{tabular}

${ }^{\mathrm{a}}$ Full set of control variables used in estimation of each equation. ${ }^{\mathrm{b}}$ Note that these questions are not mutually exclusive from the sexual partner questions or from each other.

$* \mathrm{p}<.05 * * \mathrm{p}<.01 * * * \mathrm{p}<.001 ;$ standard errors adjusted for stratification and clustering in the sample design. 
report having done so in the computerized interview. If we assume that adolescent girls in Kenya are highly unlikely to exaggerate having had premarital sex, the statistical significance and consistency of these results strongly suggest that ACASI provides a more accurate picture than face-to-face interviews of the sexual experience of adolescent girls in Kisumu. ${ }^{12}$

Nevertheless, the contrast between the results in Table 2 and those in Table 3 is puzzling. A higher percentage of respondents in the ACASI mode report experiencing highly sensitive sexual behaviors in Table 3 , yet a lower percentage report ever having sex in Table 2. To explore this issue further, we compare three different measures of

Figure 1 Predicted percent of those ever having sex by measures of sexual activity and interview mode

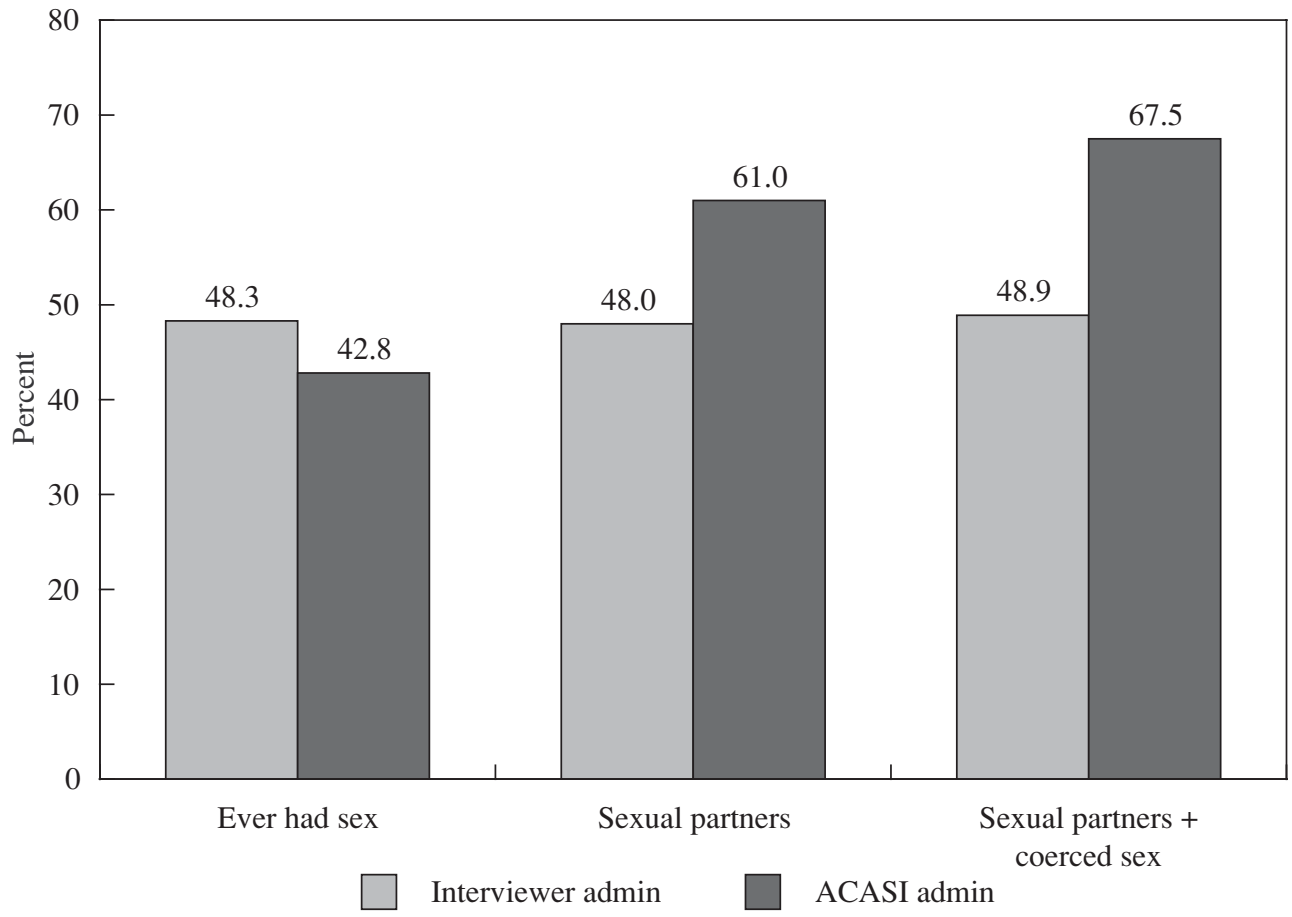

Note: Sex partners include: ever had sex with boyfriend; friend, schoolmate, or acquaintance; relative; stranger; or man ten or more years older. Coerced sex questions include: ever been tricked into sex, locked in a room for sex, or physically forced to have sex. 
sexual activity in Figure 1. The first pair of bars in the figure shows the predicted percentage of those reporting ever having sex, as seen in Table 2, while the second set is constructed from the questions about the specific sex partners shown in Table 3. The third measure of sexual activity includes those who report having had sex with a specific partner, as well as those who report having been coerced to have sex. ${ }^{13}$ The percentage of those having had sex across the three indicators changes very little in the intervieweradministrated mode, with approximately 48 percent of respondents reporting that they have had sex across the measures of sexual activity. However, this pattern is markedly different for ACASI. Although only 43 percent of respondents reported ever having sex, this figure jumps to 61 percent when sex with specific partners is used to measure sexual activity. When coerced sex is included, the percent increases to 68. These results suggest that the reported levels of premarital sexual activity among adolescent girls in Kisumu are highly dependent on the type of question used to measure sexual behavior, as well as the method of interview. The ACASI mode reveals much higher levels of sexual activity when specific sex partners and coerced sex are considered.

The consistency of responses by method and question type is explored further in Table 4, which provides a cross-tabulation of the question of ever having sex by the two

Table 4 Consistency in reporting on sexual behavior by question type and interview mode

\begin{tabular}{|c|c|c|c|c|c|c|c|c|}
\hline & \multicolumn{4}{|c|}{ Sexual partners ${ }^{\mathrm{a}}$} & \multicolumn{4}{|c|}{ Sexual partners + coerced sex ${ }^{b}$} \\
\hline & \multicolumn{2}{|c|}{$\begin{array}{c}\text { Interviewer } \\
\text { admin }\end{array}$} & \multicolumn{2}{|c|}{$\begin{array}{l}\text { ACASI } \\
\text { admin }\end{array}$} & \multicolumn{2}{|c|}{$\begin{array}{c}\text { Interviewer } \\
\text { admin }\end{array}$} & \multicolumn{2}{|c|}{$\begin{array}{l}\text { ACASI } \\
\text { admin }\end{array}$} \\
\hline & No & Yes & No & Yes & No & Yes & No & Yes \\
\hline Eve & & & & & & & & \\
\hline No & $\begin{array}{r}181 \\
(100)\end{array}$ & $\begin{array}{r}0 \\
(0.0)\end{array}$ & $\begin{array}{r}110 \\
(59.1)\end{array}$ & $\begin{array}{r}76 \\
(40.9)\end{array}$ & $\begin{array}{r}178 \\
(98.3)\end{array}$ & $\begin{array}{r}3 \\
(1.7)\end{array}$ & $\begin{array}{r}91 \\
(52.3)\end{array}$ & $\begin{array}{r}83 \\
(47.7)\end{array}$ \\
\hline Yes & $\begin{array}{r}1 \\
(0.6)\end{array}$ & $\begin{array}{r}167 \\
(99.4)\end{array}$ & $\begin{array}{r}17 \\
(11.7)\end{array}$ & $\begin{array}{r}128 \\
(88.3)\end{array}$ & $\begin{array}{r}1 \\
(0.6)\end{array}$ & $\begin{array}{r}167 \\
(99.4)\end{array}$ & $\begin{array}{r}11 \\
(7.8)\end{array}$ & $\begin{array}{r}131 \\
(92.2)\end{array}$ \\
\hline
\end{tabular}

ancludes questions on ever had sex with boyfriend; friend, schoolmate, or acquaintance; relative; stranger; or man ten or more years older.

${ }^{\mathrm{b}}$ Coerced sex includes ever been tricked into sex, locked in a room for sex, or physically forced to have sex. Note: Row percentages by interview mode are in parentheses and tally to 100 percent; consistent responses are within boxed diagonals. 
alternative measures of sexual activity from Figure 1. Note that all 349 respondents assigned to the interviewer-administered mode provided answers to each sexual activity question, whereas 53 of the 360 respondents in the ACASI mode refused to answer at least one of the sexual activity questions. Of the 53, 44 are considered missing either because they did not answer any of the sexual activity questions or because they answered at least one question but responded "no" to one or more of them. If a respondent answered "yes" to any sexual activity question even if she did not answer other questions, she is included in this analysis because she can be considered to have had sex. As we note in Hewett, Erulkar, and Mensch (2003), while high response rates are considered desirable for data analysis and are thought to be indicators of the acceptability of the questions asked, we believe they are often a consequence of respondents' feeling pressure to provide an answer to the interviewer. The nonresponse rates observed here for ACASI suggest that respondents, when not feeling compelled to answer, might decide to skip questions with which they are uncomfortable. Feeling free not to answer questions is a premise underlying most human subject protocols and, we would argue, is ethically more defensible.

The boxed diagonals in Table 4 represent consistent responses in reporting by interview mode. When a respondent answers "no" to ever having sexual intercourse and also does not report having had sex with a particular partner, she would fall in the top lefthand column and row-by interview mode — of the first panel. Alternatively, if a respondent reports that she did not have sex and subsequently admits to having had sex with a particular partner, she would fall in the top of the "off-diagonal," again by interview mode. The bottom off-diagonal represents respondents who reported having ever had sex, but did not subsequently specify any sexual partner.

In the interviewer-administered mode only four respondents are inconsistent across the three measures of sexual activity. For ACASI, a much greater number of cases, 94 out of 316, fall in the off-diagonal. The inconsistencies in ACASI are greatest for those who have answered "no" to the question "Have you ever had sex?" Of the ACASI respondents who said that they have not had sex, 41 percent subsequently indicated that they have, in fact, had sexual intercourse with a particular partner; this percent increases to 48 when coerced sex is considered. Table 4 also reveals a small percentage of incon- 
sistent cases in which ACASI respondents answered affirmatively to the ever had sex question, but then did not indicate a specific partner or that they had been coerced to have sex. It is possible in these cases that the respondents have had sex with someone other than those listed in the survey, although it is difficult to imagine who the partner might be, given that we provided an exhaustive list of categories.

Various explanations may help us understand the inconsistencies observed among ACASI respondents, although we do not have the ability to test them empirically. One possibility is that respondents become more comfortable over the course of the survey with questions about their own sexual behavior. Although respondents were asked other sensitive questions earlier in the survey, including whether they have ever drunk alcohol, smoked bhang or hashish, and whether their closest, unmarried friend had ever had sex, perhaps exposure to preliminary questions about their own sexual behavior makes them more open to probing about sexual partners and coerced sex. Of course, if they did become more comfortable one would expect the interviewer-administered mode to reveal similar patterns, unless the interviewer is enforcing consistency. Another possible explanation is that respondents' memories may be prompted by questions that refer to particular sex partners or to the context in which the sexual activity occurred. Indeed, recall ability is said to be influenced by the "vividness" of the particular sexual encounter (Catania et al. 1990). It may be that the more specific the question, the more likely it is to elicit memories of a particular sexual act. Third, respondents may compartmentalize various sexual behaviors, and therefore not perceive certain sexual activities as being included in the question "Have you ever had sex?" Respondents may not feel that being physically forced to have sex or that having sex with a relative or a stranger is the type of sex being queried about when asked whether they have ever had sexual intercourse. ${ }^{14}$ In other words, they may perceive the question to mean specifically "Have you ever had sexual intercourse with someone you cared for or loved?" This may explain the highly similar results for this question and for the question "Have you ever had sex with a boyfriend?"

Further, the level of consistency in the interviewer mode is suspect, particularly given the much lower levels of reporting, relative to ACASI, for types of sexual partners and coerced sexual activity. Interviewers were specifically trained to ask every question on the survey, regardless of the respondent's answer to the question "Have you ever had 
sex?" Interviewers were also trained not to enforce consistency or to point out inconsistent answers to the respondent. However, the exact procedures adopted by each interviewer during every interview is unknown. The possibility remains that interviewers were inclined not to continue to ask all sexual activity questions, perhaps completing the questionnaire on their own if a respondent was adamant early in the survey about not having had sex. Such a practice, if it did occur, would produce an underestimate of the amount of adolescent sexual activity among girls if, as is indicated by the ACASI results, respondents are likely to answer "no" to ever having had sex, yet respond positively to other sexual activity questions.

The differences in reporting by interviewer mode are further explored in Figure 2, which illustrates the composition of sexual activity among those admitting having had intercourse. ${ }^{15}$ The picture that emerges from the interviewer-administered surveys is that a majority ( 57 percent) of adolescent girls have had sexual intercourse only with a boyfriend, suggesting limited sexual experiences for those adolescent girls having had premarital sex. This figure, however, drops to 10 percent in the ACASI mode. With ACASI, where girls are presumably more comfortable responding to sensitive questions, a much wider range of sexual partners is revealed. Also, a much higher incidence of coerced sex is observed, with 41 percent of respondents in ACASI reporting having been tricked, locked in a room, or physically forced to have sex.

In Kisumu, respondents were given an exit interview after the main survey was completed. In both modes of interview, the exit interview was carried out by an interviewer in a face-to-face setting. Although most questions in the exit interview asked respondents about their perception of the interview-for example, did they feel bored, uncomfortable, or confused? did they have difficulty completing the questionnaire?-a selection of questions from the main survey was asked a second time. Of the sexual behavior questions, only the question "Have you ever had sex?" was asked twice. Repeating questions in surveys permits test-retest comparisons of the consistency of responses by interview mode. For ACASI, it permits an evaluation of responses in both the computerized and face-to-face interview settings. If our expectations about the reporting of premarital sex are accurate, we would expect lower levels of reported sexual activity in the face-to-face exit interview for ACASI respondents. 
Figure 2 Percentage composition of sexual partners for those reporting ever having sex Interviewer administered

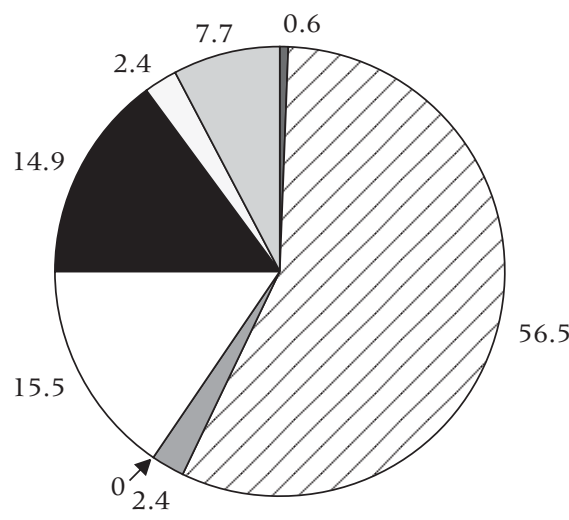

ACASI administered

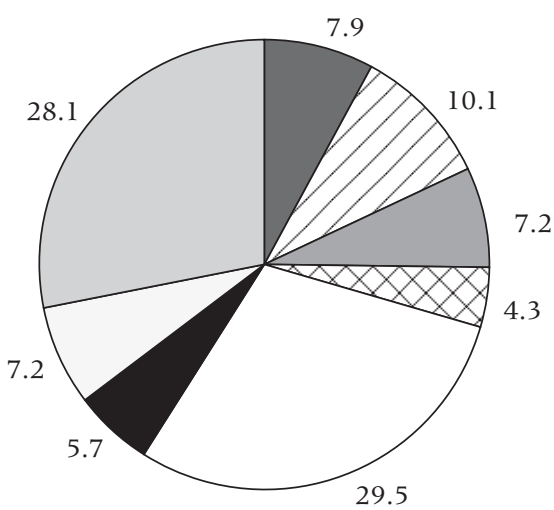

No partner specified

Boyfriend

Other partner

Coerced

Boyfriend and other partner

Boyfriend and coerced

Other partner and coerced

Boyfriend, other partner, and coerced

Note: Other partner includes sex with: friend, schoolmate, or acquaintance; relative; stranger; or a man ten or more years older. Coerced sex includes: tricked into sex, locked in a room for sex, or physically forced to have sex.

Contrary to expectations, in the exit interview 55 percent of the ACASI respondents reported having had sexual intercourse, a figure 12 percentage points higher than in the main interview (see Table 5) ${ }^{16}$ and 7 percentage points higher than the proportion reporting having had sex in the interviewer-administered mode. The higher reporting of sexual behavior in the ACASI mode is a result of the 54 respondents (or 27 percent of 
those answering "no" in the main interview) who changed their response from "no" to "yes" between the main and exit interview. These respondents appear on the surface to be more willing to reveal their sexual behavior to an interviewer. There were also 11 respondents ( 8 percent of those answering "yes" in the main survey) who did not admit to having sex in the face-to-face exit interview, but did so in the computerized interview. As suggested above, we had expected this number to be much larger.

It is difficult to understand why some ACASI respondents were willing to disclose in the face-to-face exit interview that they had had sex but did not do so in the main survey. One possibility is that respondents in the exit interview were "updating" their responses, given the fact that they had acknowledged having sexual intercourse with at least one sexual partner or having been coerced to have sex (Table 3). Of the 54 respondents in Table 5 who responded "yes" to having sex in the exit interview but not in the main survey, 75 percent had also reported a sexual partner or coerced sex in the computerized interview. However, it is unclear why they were willing to admit this in the face-to-face interview; perhaps they were concerned that the interviewer was privy to their previous answers. It is also hard to explain why the remaining 25 percent of respondents who did not report having sexual intercourse in the main interview nevertheless stated in the exit interview that they have had sexual intercourse.

Table 5 Consistency in reporting on sexual behavior between main and exit interview, by interview mode

\begin{tabular}{|c|c|c|c|c|}
\hline \multirow[b]{3}{*}{ Main survey } & \multicolumn{4}{|c|}{ Exit interview: Ever had sex } \\
\hline & \multicolumn{2}{|c|}{ Interviewer admin } & \multicolumn{2}{|c|}{ ACASI admin } \\
\hline & No & Yes & No & Yes \\
\hline $\begin{array}{l}\text { Ever had sex } \\
\text { No }\end{array}$ & $\begin{array}{r}181 \\
(100)\end{array}$ & $\begin{array}{r}0 \\
(0.0)\end{array}$ & $\begin{array}{r}143 \\
(72.6)\end{array}$ & $\begin{array}{r}54 \\
(27.4)\end{array}$ \\
\hline Yes & $\begin{array}{r}0 \\
(0.0)\end{array}$ & $\begin{array}{r}168 \\
(100)\end{array}$ & $\begin{array}{r}11 \\
(7.5)\end{array}$ & $\begin{array}{r}135 \\
(92.5)\end{array}$ \\
\hline Total & $\begin{array}{r}181 \\
(51.9)\end{array}$ & $\begin{array}{r}168 \\
(48.1)\end{array}$ & $\begin{array}{r}154 \\
(44.9)\end{array}$ & $\begin{array}{r}189 \\
(55.1)\end{array}$ \\
\hline
\end{tabular}

Note: Row percentages by interview mode are in parentheses and tally to 100 percent; consistent responses are within boxed diagonals. 
Table 6 provides further comparisons between respondents' answers in the main and exit interviews. As with the "ever had sex" question, each question was asked in the main survey and repeated in the exit interview; note that all exit interviews were conducted in a face-to-face manner. As in Tables 4 and 5, consistent responses in Table 6 are contained in the boxed diagonals. Two of the questions are considered nonsensitive, going to the market and boarding a bus alone, and two sensitive, going to the market without permission and sneaking out. The nonsensitive questions were considered neutral counterparts to the sensitive questions and were expected to show a high degree of consistency with which to compare the sensitive questions. The second set of questions were considered sensitive because the mobility of adolescent girls is highly regulated in Kenya, particularly in rural areas; activities taking place without their parents' permission are generally not considered socially acceptable.

As with the "ever had sex" question in Table 5, the interviewer-administered mode across the four questions in Table 6 displays a high level of consistency between the main and exit interview, with a small number of cases in the off-diagonals. In the ACASI mode, however, varied patterns of inconsistency are revealed. The top half of the first panel indicates that two-thirds of respondents who reported that they had not gone to the market in the main ACASI interview told the interviewer that they had done so in the exit interview. For the second question, shown in the bottom half of the first panel, the pattern changes, with more than a third of the respondents reporting in the exit interview that they had not boarded a bus alone when they had answered affirmatively to this question in the main interview.

Turning to the more sensitive questions in the bottom panel of Table 6 , the pattern of inconsistencies is similar to the question about "boarding a bus alone." Those who admitted they had gone to the market or sneaked out without their parents' permission in ACASI were less likely to report these behaviors in the face-to-face exit interview. Nearly three-quarters of respondents reported that they had gone to the market without their parents' permission in the computerized interview, but then reversed their answer in the exit interview. And about half of respondents who admitted to sneaking out without permission in the main survey denied doing so in the exit interview. 
Table 6 Consistency in reporting on nonsensitive and sensitive behavior between main and exit interview, by interview mode

\begin{tabular}{|c|c|c|c|c|}
\hline \multirow[b]{3}{*}{ Main survey } & \multicolumn{4}{|c|}{ Exit interview $^{\mathrm{a}}$} \\
\hline & \multicolumn{2}{|c|}{ Interviewer admin } & \multicolumn{2}{|c|}{ ACASI admin } \\
\hline & No & Yes & No & Yes \\
\hline & \multicolumn{4}{|c|}{ Nonsensitive behaviors } \\
\hline $\begin{array}{l}\text { Gone to market } \\
\text { No }\end{array}$ & $\begin{array}{r}33 \\
(94.3)\end{array}$ & $\begin{array}{r}2 \\
(5.7)\end{array}$ & $\begin{array}{r}50 \\
(34.0)\end{array}$ & $\begin{array}{r}97 \\
(66.0)\end{array}$ \\
\hline Yes & $\begin{array}{r}6 \\
(1.9)\end{array}$ & $\begin{array}{r}308 \\
(98.1)\end{array}$ & $\begin{array}{r}11 \\
(5.4)\end{array}$ & $\begin{array}{r}194 \\
(94.6)\end{array}$ \\
\hline Total & $\begin{array}{r}39 \\
(11.2)\end{array}$ & $\begin{array}{r}310 \\
(88.8)\end{array}$ & $\begin{array}{r}61 \\
(17.3)\end{array}$ & $\begin{array}{r}291 \\
(82.7)\end{array}$ \\
\hline $\begin{array}{l}\text { Boarded a bus al } \\
\text { No }\end{array}$ & $\begin{array}{r}217 \\
(99.5)\end{array}$ & $\begin{array}{r}1 \\
(0.5)\end{array}$ & $\begin{array}{r}218 \\
(87.2)\end{array}$ & $\begin{array}{r}32 \\
(12.8)\end{array}$ \\
\hline Yes & $\begin{array}{r}4 \\
(3.0)\end{array}$ & $\begin{array}{r}127 \\
(97.0)\end{array}$ & $\begin{array}{r}37 \\
(37.0)\end{array}$ & $\begin{array}{r}63 \\
(63.0)\end{array}$ \\
\hline Total & $\begin{array}{r}221 \\
(63.3)\end{array}$ & $\begin{array}{r}128 \\
(36.7)\end{array}$ & $\begin{array}{r}255 \\
(72.9)\end{array}$ & $\begin{array}{r}95 \\
(27.1)\end{array}$ \\
\hline
\end{tabular}

Gone to market without permission No

Yes

Total

\begin{tabular}{|c|c|c|c|}
\hline $\begin{array}{r}280 \\
(98.2)\end{array}$ & $\begin{array}{r}5 \\
(1.8)\end{array}$ & $\begin{array}{r}222 \\
(94.1)\end{array}$ & $\begin{array}{r}14 \\
(5.9)\end{array}$ \\
\hline $\begin{array}{r}5 \\
(7.8)\end{array}$ & $\begin{array}{r}59 \\
(92.2)\end{array}$ & $\begin{array}{r}84 \\
(73.0)\end{array}$ & $\begin{array}{r}31 \\
(27.0)\end{array}$ \\
\hline $\begin{array}{r}285 \\
(81.6)\end{array}$ & $\begin{array}{r}64 \\
(18.4)\end{array}$ & $\begin{array}{r}306 \\
(87.2)\end{array}$ & $\begin{array}{r}45 \\
(12.8)\end{array}$ \\
\hline
\end{tabular}

Sneaked out without permission

No

Yes

Total

\begin{tabular}{|r|r|r|r|}
293 & 6 & $\begin{array}{r}260 \\
(93.5)\end{array}$ & $\begin{array}{r}18 \\
(68.5)\end{array}$ \\
\hline 2 & $(2.0)$ & 36 & 37 \\
$(4.0)$ & $(96.0)$ & $(49.3)$ & $(50.7)$ \\
295 & 54 & 296 & 55 \\
$(84.5)$ & $(15.5)$ & $(84.3)$ & $(15.7)$ \\
\hline
\end{tabular}

${ }^{a}$ Questions were asked by an interviewer in a face-to-face context at the end of the survey.

Note: Row percentages by interview mode are in parentheses and tally to 100 percent; consistent responses are within boxed diagonals. 
The inconsistencies in the nonsensitive questions in Table 6 among ACASI respondents were unexpected, but perhaps understandable. Adolescents might exaggerate going to the market in the face-to-face interview in an attempt to appear more mature and independent. This would lead to an over-reporting of this activity for ACASI respondents in the exit interview and would produce the pattern of results observed in Table 6. As for the second question, perhaps it is inaccurate to label it as "nonsensitive." Although going to the market is considered a common and acceptable activity for adolescent girls, riding a bus alone may be potentially precarious for an unsupervised, unmarried adolescent girl. Respondents may therefore feel reluctant to admit having done this. ${ }^{17}$

Responses to the sensitive questions in the bottom panel of Table 6 follow the expected pattern. The lower levels of reporting in the face-to-face exit interview for ACASI respondents relative to the main interview provide support for the notion that adolescents vary answers to correspond to perceived social norms. In fact, comparing ACASI with the interviewer-administered mode in the main survey reveals that respondents were almost twice as likely (32 percent versus 18 percent) to report going to the market without their parents' permission in the computerized interview. They were also more likely to report sneaking out at night in ACASI (21 percent versus 14 percent). ${ }^{18}$ These results parallel the reporting of sexual partners and coerced sexual activity in Table 3.

\section{DISCUSSION}

We have argued in this paper and elsewhere (Mensch, Hewett, and Erulkar 2003) that the interaction between the interviewer and respondent has an effect on answers to sensitive questions. Our review of survey research on adolescent sexual activity in developing countries that has relied on face-to-face interviews reveals patterns of sexual behavior that appear inconsistent and implausible. Findings of widely varying levels of sexual activity among boys and girls of similar ages, and of sharply different levels of premarital sex for adolescents across sub-Saharan African countries that one would ex-

pect to have similar levels, suggest problems in the reporting of sexual behavior in adolescent surveys.

It appears that both respondents' perceptions of social norms and their own notions of acceptable behavior influence their willingness to respond candidly to interview 
questions. Respondents, particularly adolescent girls, are likely to feel pressure to conform to societal expectations. By modifying their answers to increase conformity with these norms, respondents minimize the perceived social distance between themselves and the interviewer. This premise places a premium on the respondents' beliefs regarding social norms and their perceptions of the interviewer's opinions and values (Sudman, Bradburn, and Schwarz 1977). Using various social cues, such as gender, age, ethnic group, and education, and inferences derived from verbal and nonverbal cues of the interviewer, the respondents likely adjust their answers to minimize any dissonance generated in the context of the interview.

The results outlined in this paper present fresh evidence that the type of questions asked and the mode of survey administration significantly affect the responses of adolescents to sensitive questions. However, as observed here, these effects are not always predictable or easily explicable. What appears clear is that adolescent girls in Kisumu district, Kenya, report greater levels of highly stigmatized sexual activity in audio computer-assisted self-interviewing relative to the face-to-face interviewer-administered mode. Respondents are significantly more likely to report in ACASI that they have had sex with a relative, stranger, or older man, and/or have been coerced to have sex. As we have shown, ACASI produces a more diverse picture of adolescent sexual activity than the face-to-face interviewer-administered method, a picture which suggests that adolescent girls in Kenya have more complicated, and clearly more perilous, sex lives than traditional surveys of sexual activity indicate. These findings have implications for program managers and policymakers seeking to meet the reproductive health needs of young women in sub-Saharan Africa.

The fact that ACASI does not perform better for the "ever had sex" question, in either Kisumu or Nyeri, leads to some unexpected findings regarding the consistency of responses for questions asked twice during the survey - once during the main survey and again in the face-to-face exit interview. Whereas the interviewer-administered mode produces highly consistent reporting on such questions, the ACASI respondents are apt to change their responses over the course of the interview. They are also more willing to admit to the interviewer in the face-to-face exit interview that they have had sex. Some explanations were explored to address these findings, including the possibility that re- 
spondents were updating their responses after responding positively to other sexual behavior questions.

Although this study examined aggregate levels of reporting of sexual behavior by interview mode, we have not considered the individual-level variation in reaction of particular respondents to the social context of the interview. Instead, we have assumed that the effect of the interview mode is the same for all respondents. However, it is likely that some respondents are more sensitive than others to the social context of the interview. Some will feel more pressure to conform to social norms, while others are more apt to report candidly irrespective of the type of interview. Considering psychosocial models of interaction and identifying which adolescents are most affected by interview mode are topics for future research. Although these topics have been addressed in the United States (e.g., Sudman, Bradburn, and Schwarz 1996), the applicability of these ideas to developing countries has not been explored. 
Appendix Table 1 Selected characteristics of respondents by interview mode ${ }^{\mathrm{a}}$

\begin{tabular}{|c|c|c|}
\hline & $\begin{array}{l}\text { Interviewer } \\
\text { administered }\end{array}$ & $\begin{array}{c}\text { ACASI } \\
\text { administered }\end{array}$ \\
\hline \multicolumn{3}{|l|}{ Respondent characteristics } \\
\hline Mean age (years) & 17.0 & 17.0 \\
\hline Ethnicity: Luo & 80.2 & 74.3 \\
\hline Urban, peri-urban residence & 43.8 & 48.3 \\
\hline Catholic & 28.9 & 30.6 \\
\hline $\begin{array}{l}\text { Mean no. of times attended religious } \\
\text { services in the last week }\end{array}$ & 1.2 & 2.9 \\
\hline Completed primary school & 24.9 & 16.0 \\
\hline Attended, completed secondary school & 14.6 & 8.7 \\
\hline Currently enrolled in school & 39.0 & 52.7 \\
\hline Currently works for cash & 15.2 & 26.6 \\
\hline \multicolumn{3}{|l|}{ Household structure } \\
\hline Lives with both parents & 40.4 & 44.0 \\
\hline Lives with one parent & 25.8 & 36.1 \\
\hline Mean no. of adolescent boys in household & .20 & .24 \\
\hline Mean no. of adolescent girls in household & 1.2 & 1.2 \\
\hline $\begin{array}{l}\text { Mean no. of people slept in household } \\
\text { previous night }\end{array}$ & 5.4 & 4.6 \\
\hline \multicolumn{3}{|l|}{ Household characteristics } \\
\hline $\begin{array}{l}\text { Mean no. of items owned: livestock, cash crops, } \\
\text { or land }\end{array}$ & 1.6 & 1.4 \\
\hline Household has piped water & 18.9 & 30.4 \\
\hline Household has well water & 33.0 & 21.9 \\
\hline Household has flush toilet & 20.1 & 26.7 \\
\hline Household has finished floors & 47.9 & 38.0 \\
\hline Household has electricity & 24.6 & 33.7 \\
\hline Mean no. of rooms used for sleeping & 2.1 & 2.0 \\
\hline Sample size & 349 & 360 \\
\hline
\end{tabular}

${ }^{a}$ Numbers are percentages unless otherwise indicated. 


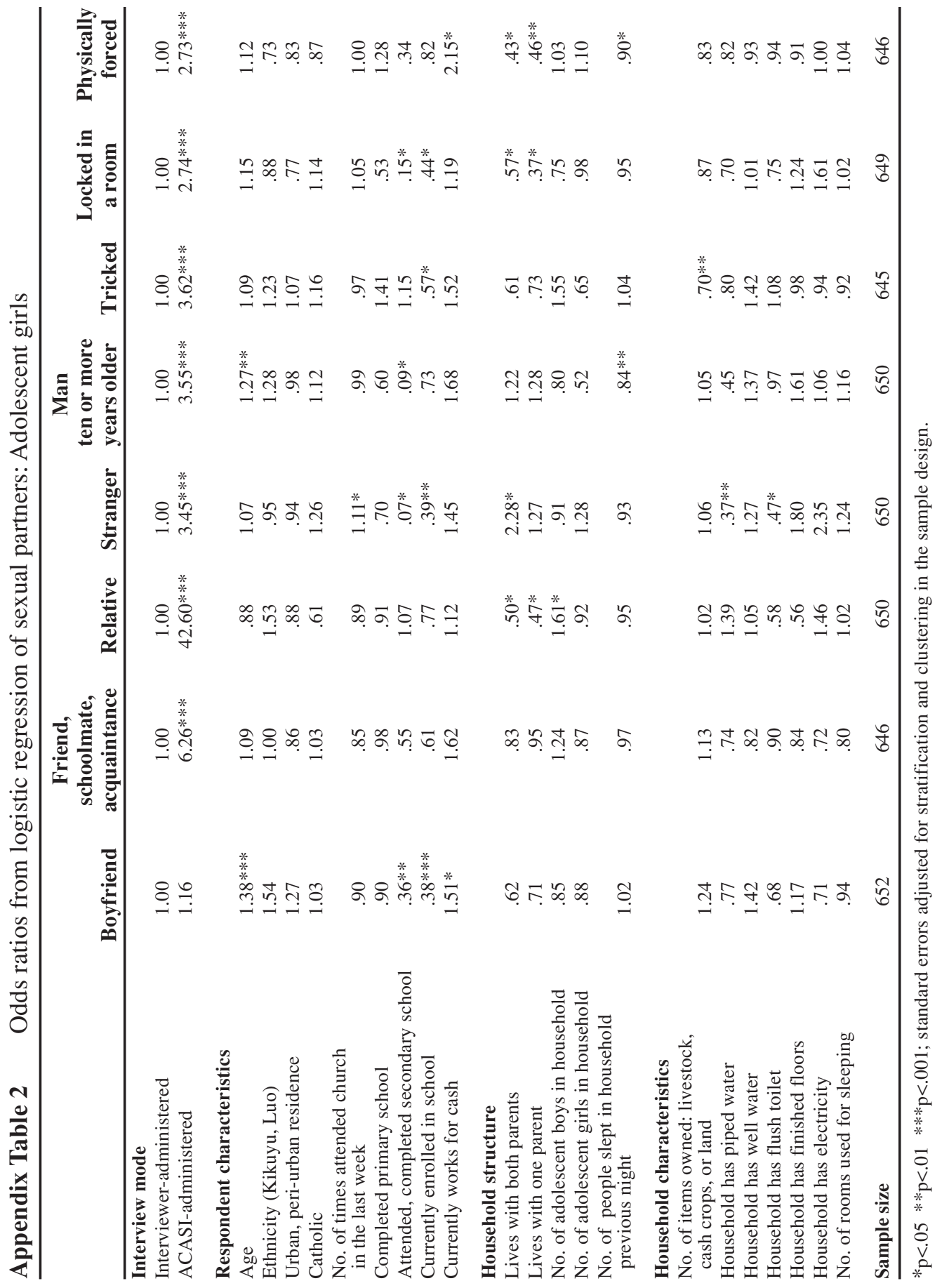


Appendix Figure 1 Percentage composition of sexual partners for those reporting never having had sex

Interviewer administered

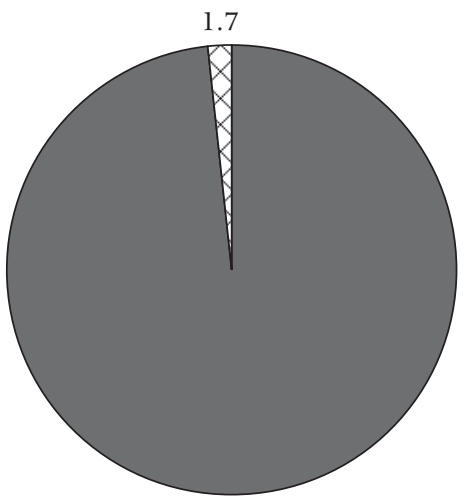

98.3

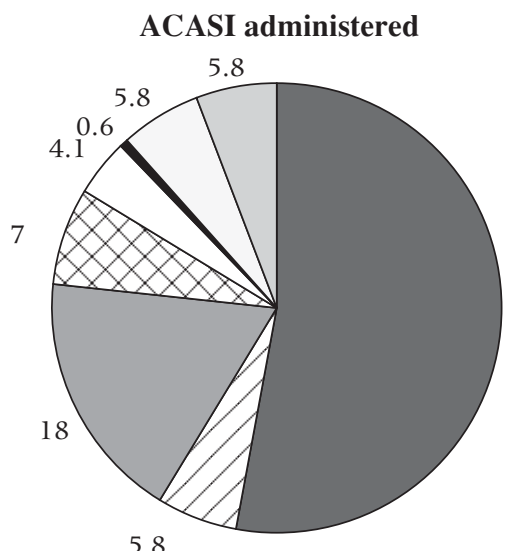

No partner specified

$\square$ Boyfriend

Other partner

冈 Coerced

$\square$ Boyfriend and other partner

Boyfriend and coerced

$\square$ Other partner and coerced

Boyfriend, other partner, and coerced

52.9

Note: Other partner includes sex with: friend, schoolmate, or acquaintance; relative; stranger; or a man ten or more years older. Coerced sex includes: tricked into sex, locked in a room for sex, or physically forced to have sex. 


\section{NOTES}

1 The political environment in Nyeri has probably changed since we completed data collection. In December 2002, the opposition National Rainbow Coalition (NARC) and its candidate Mwai Kibaki-a Kikuyu—won the national presidential elections.

2 This literature review draws heavily from Hewett, Erulkar, and Mensch (2003).

3 See Couper and Nicholls (1998) and Turner et al. (1998) for overviews of the development of computerized interviewing and its use in surveys with sensitive questions.

$4 \quad$ Urban and rural designations were determined by the Office of the Central $\mathrm{Bu}$ reau of Statistics, Kenya.

5 Statistics for Kisumu were taken from Ferry et al. (2001), while statistics for Kenya were calculated from the 1998 Kenyan DHS women's files. Both sets of estimates are for women 20-49 years of age.

6 Within provinces, districts can be further subdivided geographically by location and sublocation. Sublocations are the lowest administrative unit in Kenya, roughly comparable to a village. The size of sublocations varies from a few hundred households to 10,000 or more depending on urban, rural, and geographic settlement patterns. Selection of sublocations within the two districts was based on probabilities proportional to size. In Kisumu, sublocations were first stratified by urban and rural areas.

7 Determination of the sample sizes was based upon the expected differences in reporting levels across interviewing modes, the significance criterion $\alpha$, and the power of the significance test (Cohen 1992).

8 Only one adolescent per household was assigned to the study. If there was more than one adolescent in the age range, one was selected randomly, on the basis of a "Kish" grid. 
9 Although these questions were subsequently asked, they did not immediately follow the initial question on sexual intercourse.

10 The logistic regressions included robust estimates of the standard errors to adjust for potential homogeneity within the primary sampling unit resulting from the cluster design of the sample.

11 The complete set of regression results is provided in Appendix Table 2.

12 One concern of repeatedly asking the respondent whether she has had sex with a boyfriend, friend, relative, etc. after she had previously responded that she had not "ever had sex" is that the respondent would ultimately say she has had sex for the sake of agreeing to something being asked. If this were the case, the pattern of results in Table 3 would likely show an ascending pattern of predicted percentages by interview mode, since the order of questions in Table 3 parallels the order asked in the survey. However, Table 3 does not provide evidence of this response pattern.

13 This measure takes on the value of one if the respondent reports having had sex with any of the possible partners listed in Table 3 or if she reports having been coerced to have sex.

14 Note that these categories are not mutually exclusive. For instance, a respondent may have been tricked into having sex by her boyfriend or physically forced to have sex by a relative.

15 Although not discussed, the same breakdown for those reporting never having had sex is provided in Appendix Figure 1.

16 In contrast to Table 4, only 17 of 360 respondents are missing from the ACASI analysis shown in Table 5. These 17 did not answer the "ever had sex" question in the ACASI part of the survey but answered the "ever had sex" question in the exit interview; this pattern is consistent with our observation that respondents feel compelled to answer questions posed by interviewers. 
17 We thank our Kenyan colleagues Lucy Ng'ang'a and Francis Ayuka for helping us interpret this finding.

18 These are row percentage totals whose calculation is not shown in Table 6.

\section{REFERENCES}

Aquilino, William S. 1994. "Interview mode effects in surveys of drug and alcohol use: A field experiment," Public Opinion Quarterly 58(2): 210-240.

Aquilino, William S. and Leonard A. Lo Scuito. 1990. "Effects of interviewer mode on self-reported drug use," Public Opinion Quarterly 54(3): 362-395.

Beebe, Timothy J., Patricia A. Harrison, James A. Mcrae, Ronald E. Anderson, and Jayne Fulkerson. 1998. "An evaluation of computer assisted self-interviews in a school setting,” Public Opinion Quarterly 62(4): 623-632.

Boekeloo, B.O., L. Schiavo, D.L. Rabin, R.T. Conlon, C.S. Jordan, and D.J. Mundt. 1994. "Self-reports of HIV risk factors by patients at a sexually transmitted disease clinic: Audio vs. written questionnaires," American Journal of Public Health 8(5): 754-760.

Buvé, A., M. Caraël, R.J. Hayes, B. Auvert, B. Ferry, N.J. Robinson, S. Anagonou, L. Kanhonou, M. Laourou, S. Abega, E. Akam, L. Zekeng, J. Chege, M. Kahindo, N. Rutenberg, F. Kaona, R. Musonda, T. Sukwa, L. Morison, H.A. Weiss, and M. Laga, for the Study Group on Heterogeneity of HIV Epidemics in African Cities. 2001. "Multicentre study on factors determining differences in rate of spread of HIV in sub-Saharan Africa: Methods and prevalence of HIV infection," AIDS 15(Supplement 4, August): S5-S14.

Catania, Joseph A., David Gibson, Dale D. Chitwood, and Thomas J. Coates. 1990. "Methodological problems in AIDS behavior research: Influences on measurement error and participation bias in studies of sexual behavior," Psychological Bulletin 108(3): 339-362.

Cohen, Jacob. 1992. “A power primer,” Psychological Bulletin 112(1): 155-159.

Copas, Andrew J., Anne M. Johnson, and Jane Wadsworth. 1997. “Assessing participa- 
tion bias in a sexual behaviour survey: Implications for measuring HIV risk," AIDS 11: 783-790.

Couper, M.P. and William L. Nicholls II. 1998. "The history and development of computer assisted survey information collection methods," pp. 1-22 in Mick P. Couper et al. (eds.), Computer Assisted Survey Information Collection. New York: Wiley.

Des Jarlais, D. et al. 1999. "Audio-computer interviewing to measure risk behavior for HIV among injecting drug users: A quasi-randomized trial," Lancet 353: 1657 1661.

Fenton, Kevin A., Anne M. Johnson, Sally McManus, and Bob Erens. 2001. "Measuring sexual behavior: Methodological challenges in survey research," Sexually Transmitted Infections 77: 84-92.

Ferry, B., M. Caraël, A. Buvé, B. Auvert, M. Laourou, L. Kanhonou, M. de Loenzien, E. Akam, J. Chege, and F. Kaona. 2001. "Comparison of key parameters of sexual behavior in four African urban populations with different levels of HIV infection," AIDS 15 (suppl 4): S41-S50.

Fu, Haishan, Jacqueline E. Darroch, Stanley Henshaw, and Elizabeth Kolb. 1998. "Measuring the extent of abortion underreporting in the 1995 National Survey of Family Growth," Family Planning Perspectives 30(3): 128-138.

Glynn, J.R., M. Caraël, B. Auvert, M. Kahindo, J. Chege, R. Musonda, F. Kaona, A. Buvé, for the Study Group on the Heterogeneity of HIV Epidemics in African Cities. 2001. "Why do young women have a much higher prevalence of HIV than young men? A study in Kisumu, Kenya and Ndola, Zambia," AIDS 15(Supplement 4, August): S51-S60.

Hewett, Paul C., Annabel S. Erulkar, and Barbara S. Mensch 2003. "The feasibility of computer-assisted survey interviewing in Africa: Experience from two rural districts in Kenya," Policy Research Division Working Paper, no. 168. New York: Population Council.

Jobe, J.B., W.F. Pratt, R. Tourangeau, A. Baldwin, and K. Rasinski. 1997. "Effects of interview mode on sensitive questions in a fertility survey," pp. 311-329 in L. Lyberg (ed.), Survey Measurement and Process Quality. New York: Wiley. 
Johnson, A.M. et al. 2001. "Effect of computer assisted self interviews on reporting of sexual HIV risk behaviors in a general population sample: A methodological experiment," AIDS 15: 111-115.

Kyrsan, Maria. 1998. "Privacy and the expression of white racial attitudes: A comparison across three contexts," Public Opinion Quarterly 62(4): 506-544.

Lara, Diana, Charlotte Ellertson, Claudia Diaz, and Jennifer Strickler. 2001. "Measuring the prevalence of induced abortion in Mexico City: Comparison of four methodologies," paper presented at the 24th Population Conference of the International Union for the Scientific Study of Population, Salvador de Bahia.

Macalino, G., D. Celentano, S. Strathdee, C. Latkin, and D. Vlahov. 2002. "Risk behaviors by audio computer-assisted self-interviews among HIV-seropositive and HIVseronegative injection drug users," AIDS Education and Prevention 14(5): $367-$ 378.

Mensch, Barbara S., Paul C. Hewett, and Annabel S. Erulkar 2003. "The reporting of sensitive behavior among adolescents: A methodological experiment in Kenya," Demography 40(2): 247-268.

Mensch, Barbara S., Paul C. Hewett, and Annabel S. Erulkar. 2001. "The reporting of sensitive behavior among adolescents: A methodological experiment in Kenya," Research Division Working Paper no. 151. New York: Population Council.

Metzger, D.S., B. Koblin, H. Navaline, C. Turner, F. Valenti, S. Holte, M. Gross, A. Sheon, H. Miller, P. Cooley, and G.R. Seage 3rd. 2000. "Randomized controlled trial of audio computer-assisted self-interviewing: Utility and acceptability in longitudinal studies. HIVNET Vaccine Preparedness Study Protocol Team," American Journal of Epidemiology 152(2): 99-106.

Millstein, S.G. and C.E. Irwin. 1983. "Acceptability of computer-acquired sexual histories in adolescent girls," Journal of Pediatrics 103: 815-819.

O’Reilly, J., M. Hubbard, J. Lessler, P. Biemer, and C. Turner. 1994. “Audio and video computer assisted self-interviewing: Preliminary tests of new technology for data collection," Journal of Official Statistics 10: 197-214. 
Rumakom, Patchara, Philip Guest, Waranuch Chinvarasopak, Watit Utmarat, and Jiraporn Sontanakanit. 1999. "Obtaining accurate responses to sensitive questions: A comparison of two data collection techniques." Unpublished manuscript. Population Council, Bangkok, Thailand.

Sudman, Seymour, Norman M. Bradburn, and Norbert Schwarz. 1977. "Modest expectations: The effects of interviewers' prior expectations on responses," Sociological Methods and Research 6: 171-182.

Sudman, Seymour, Norman M. Bradburn, and Norbert Schwarz. 1996. Thinking About Answers: The Application of Cognitive Processes to Survey Methodology. San Francisco: Jossey-Bass Publishers.

Tourangeau, Roger and Tom W. Smith. 1996. "Asking sensitive questions: The impact of data collection mode, question format, and question context," Public Opinion Quarterly 60(2): 275-304.

Turner, C.F., L. Ku, M. Rogers, L.D. Lindberg, J.H. Pleck, and F.L. Sonenstein. 1998. "Adolescent sexual behavior, drug use and violence: Increased reporting with computer survey technology," Science 280: 867-873.

UNAIDS. 2000. National AIDS Programmes: A Guide to Monitoring and Evaluation. Geneva: UNAIDS.

UNAIDS and WHO. 1998. "Epidemiological fact sheet on HIV/AIDS and sexual transmitted diseases: Kenya," accessed online, 16 June 2000 at http://www.who.int/ emc-hiv/fact_sheets.html

van de Wijgert, Janneke, Nancy Padian, Stephen Shiboski, and Charles Turner. 2000. "Is audio computer-assisted self-interviewing a feasible method of surveying in Zimbabwe?” International Journal of Epidemiology 29: 885-890.

Voeten, Helene, E.I. Meester, O.B. Egesah, and J.D.F. Habbema. 2000. "Experiences with method triangulation in a study on sexual behavior of young adults 15-29 years in Nyanza province, Kenya," paper presented at the IUSSP Conference on Partnership Networks, Chiang Mai, Thailand.

Williams, M.L., R.C. Freeman, A.M. Brown, Z. Zhao, W.N. Elwood, C. Gordon, P. 
Young, R. Rusek, and C.A. Signes. 2000. "A comparison of the reliability of selfreported drug use and sexual behaviors using computer assisted versus face to face interviewing," AIDS Education and Prevention 12(3): 199-213.

Zaba, B., J.T. Boerma, E. Pisani, and N. Baptiste 2002. "Estimation of levels and trends in age at first sex from African demographic surveys using survival analysis," paper presented at the Annual Meeting of the Population Association of America, Atlanta, 9-11 May. 


\section{POLICY RESEARCH DIVISION WORKING PAPERS}

Recent back issues available at www.popcouncil.org/publications/wp/prd/rdwplist.html.

144 John Bongaarts, "Household size and composition in the developing world."

145 John B. Casterline, Zeba A. Sathar, and Minhaj ul Haque, "Obstacles to contraceptive use in Pakistan: A study in Punjab."

146 Zachary Zimmer, Albert I. Hermalin, and Hui-Sheng Lin, "Whose education counts? The impact of grown children's education on the physical functioning of their parents in Taiwan."

147 Philomena Nyarko, Brian Pence, and Cornelius Debpuur, "Immunization status and child survival in rural Ghana."

*148 John Bongaarts and Zachary Zimmer, "Living arrangements of older adults in the developing world: An analysis of DHS household surveys."

149 Markos Ezra, "Ecological degradation, rural poverty, and migration in Ethiopia: A contextual analysis."
150 Cynthia B. Lloyd, Sahar El Tawila, Wesley H. Clark, and Barbara S. Mensch, "Determinants of educational attainment among adolescents in Egypt: Does school quality make a difference?"

*151 Barbara S. Mensch, Paul C. Hewett, and Annabel Erulkar, "The reporting of sensitive behavior among adolescents: A methodological experiment in Kenya."

152 John Bongaarts, "The end of the fertility transition in the developed world."

*153 Mark R. Montgomery, Gebre-Egziabher Kiros, Dominic Agyeman, John B. Casterline, Peter Aglobitse, and Paul Hewett, "Social networks and contraceptive dynamics in southern Ghana."

*154 Paul C. Hewett and Mark R. Montgomery, "Poverty and public services in developing-country cities."

* No longer available as a printed publication. Download electronic file from website only. 
155 Zachary Zimmer, Linda G. Martin, and Ming-Cheng Chang, "Changes in functional limitations and survival among the elderly in Taiwan: 1993, 1996, and 1999."

156 John Bongaarts and Griffith Feeney, "How long do we live?"

157 Zachary Zimmer and Sovan Kiry Kim, "Living arrangements and socio-demographic conditions of older adults in Cambodia."

158 Geoffrey McNicoll, "Demographic factors in East Asian regional integration."

159 Carol E. Kaufman, Shelley Clark, Ntsiki Manzini, and Julian May, "How community structures of time and opportunity shape adolescent sexual behavior in South Africa."

*160 Julia Dayton and Martha Ainsworth, "The elderly and AIDS: Coping strategies and health consequences in rural Tanzania."

161 John Bongaarts, "The end of the fertility transition in the developing world."
162 Naomi Rutenberg, Carol E. Kaufman, Kate Macintyre, Lisanne Brown, and Ali Karim, "Pregnant or positive: Adolescent childbearing and HIV risk in South Africa."

163 Barbara S. Mensch, Wesley H. Clark, and Dang Nguyen Anh, "Premarital sex in Vietnam: Is the current concern with adolescent reproductive health warranted?"

164 Cynthia B. Lloyd, Cem Mete, and Zeba A. Sathar, "The effect of gender differences in primary school access, type, and quality on the decision to enroll in rural Pakistan."

165 Kelly Hallman, Agnes R. Quisumbing, Marie Ruel, and Bénédicte de la Brière, "Childcare, mothers' work, and earnings: Findings from the urban slums of Guatemala City."

*166 Carol E. Kaufman and Stavros E. Stavrou, “'Bus fare, please': The economics of sex and gifts among adolescents in urban South Africa."

*167 Dominic K. Agyeman and John B. Casterline, "Social organization and reproductive behavior in southern Ghana."

\footnotetext{
* No longer available as a printed publication. Download electronic file from website only.
} 
168 Paul C. Hewett, Annabel S. Erulkar, and Barbara S. Mensch, "The feasibility of computer-assisted survey interviewing in Africa: Experience from two rural districts in Kenya."

169 Zachary Zimmer and Julia Dayton, "The living arrangements of older adults in sub-Saharan Africa in a time of HIV/AIDS."

170 Ravai Marindo, Steve Pearson, and John B. Casterline, "Condom use and abstinence among unmarried young people in Zimbabwe: Which strategy, whose agenda?"

171 Sajeda Amin and Nagah H. AlBassusi, "Wage work and marriage: Perspectives of Egyptian working women."

172 Zachary Zimmer, Napaporn Chayovan, Hui-Sheng Lin, and Josefina Natividad, "How indicators of socioeconomic status relate to physical functioning of older adults in three Asian societies."

173 Paul Demeny, "Population policy: A concise summary."

174 Geoffrey McNicoll, "Population and development: An introductory view."

175 James F. Phillips, Tanya C. Jones, Frank K. Nyonator, and Shruti Ravikumar, "Evidence-based development of health and family planning programs in Bangladesh and Ghana."
176 Cynthia B. Lloyd and Paul C. Hewett, "Primary schooling in sub-Saharan Africa: Recent trends and current challenges."

177 John Bongaarts, "Completing the fertility transition in the developing world: The role of educational differences and fertility preferences."

178 Elizabeth F. Jackson, Patricia Akweongo, Evelyn Sakeah, Abraham Hodgson, Rofina Asuru, and James F. Phillips, "Women's denial of having experienced female genital cutting in northern Ghana: Explanatory factors and consequences for analysis of survey data."

179 John Bongaarts and Griffith Feeney, "Estimating mean lifetime."

180 Frank K. Nyonator, J. Koku AwoonorWilliams, James F. Phillips, Tanya C. Jones, and Robert A. Miller, "The Ghana Community-based Health Planning and Services Initiative: Fostering evidence-based organizational change and development in a resource-constrained setting."

181 Zachary Zimmer, Linda G. Martin, and Hui-Sheng Lin, "Determinants of old-age mortality in Taiwan."

182 Paul C. Hewett, Barbara S. Mensch, and Annabel S. Erulkar, "Consistency in the reporting of sexual behavior among adolescent girls in Kenya: A comparison of interviewing methods." 